\title{
A STRATIGRAPHIC RECORD OF AN ICE CORE FROM THE YAMATO METEORITE ICE FIELD, ANTARCTICA
}

\author{
by
}

\author{
Masayoshi Nakawo, Masayasu Nagoshi and Shinji Mae
}

(Department of Applied Physics, Faculty of Engineering, Hokkaido University, Sapporo 060, Japan)

\begin{abstract}
Measurements of density, total gas content, $\delta^{18} \mathrm{O}$, and electrical conductivity were carried out along a core $100 \mathrm{~m}$ long. A profile of in-situ bubble pressure was obtained from the data on density and total gas content, taking into account the volume relaxation of the core in the period between core recovery and density determination. The bubble pressure was appreciably higher than the overburden pressure at corresponding depths. It was considered that the pressure difference was caused by the continuous lifting of the ice, since ice flow was obstructed in the blue-ice area. From the profile of the pressure difference, the vertical distribution of the upward velocity was calculated, which provided a time-scale for the core. It was found that the $100 \mathrm{~m}$ long core represented a record of about $10^{4}-10^{5} \mathrm{a}$. Since the surface ice was considered to represent a few tens of thousand years B.P., the data obtained on total gas content, $\delta^{18} \mathrm{O}$, and electrical conductivity would describe the variations in the climate as well as in the ice sheet during the last glacial period.
\end{abstract}

\section{INTRODUCTION}

A large number of meteorites have been found on the blue-ice area near such nunataks as the Yamato Mountains and the Allan Hills on the Antarctic ice sheet (e.g. Yanai 1979, Cassidy and others 1977).

The dynamic behaviour of the ice sheet around the blue-ice areas has been examined with a view to explaining the mechanism of meteorite accumulation (Nishio and others 1982, Whillans and Cassidy 1983, Azuma and others 1985). It was revealed that the flow vector inclined upwards relative to the surface, and the continuous evaporation of the blue ice was compensated for by the vertical movement.
Hence it was thought that those meteorites were once buried in the accumulation area, and had been transported by the ice flow, to reappear in the blue-ice area (Nagata 1978). The meteorites accumulated at the surface over a long period, during the sublimation of the ice.

These studies indicate that relatively old ice is exposed in blue-ice areas, and various records of the climatic change as well as of the ice-sheet variation could be obtained by examining ice cores taken from ablation areas. It is generally to be expected that a relatively short core will preserve a longish history (Whillans and Cassidy 1983, Azuma and others 1985).

\section{CORE DESCRIPTION}

A $101.4 \mathrm{~m}$ long core $(\phi=0.12 \mathrm{~m})$ was recovered from the southern part of the meteorite ice field (near the Yamato Mountains, Antarctica) by the 24th Japanese Antarctic Research Expedition. The drilling was carried out for about a week in December 1983 .

The core was cut into $0.5 \mathrm{~m}$ long segments, and transported to the icebreaker Shirase. Air temperature was in the range of $-10^{\circ}$ to $-20^{\circ} \mathrm{C}$ during the month taken by the oversnow traverse. It was considered that the core segments were exposed to the same range of temperatures or, at most, to temperatures only a few degrees higher, since the core boxes were covered by a specially designed sheet which effectively reflected solar radiation.

Samples were stored on the icebreaker at $-20^{\circ} \mathrm{C}$, until they were eventually used for various analyses in Japan. It was about 16 months after the recovery of the core that it was subjected both to total gas content and to density determination.
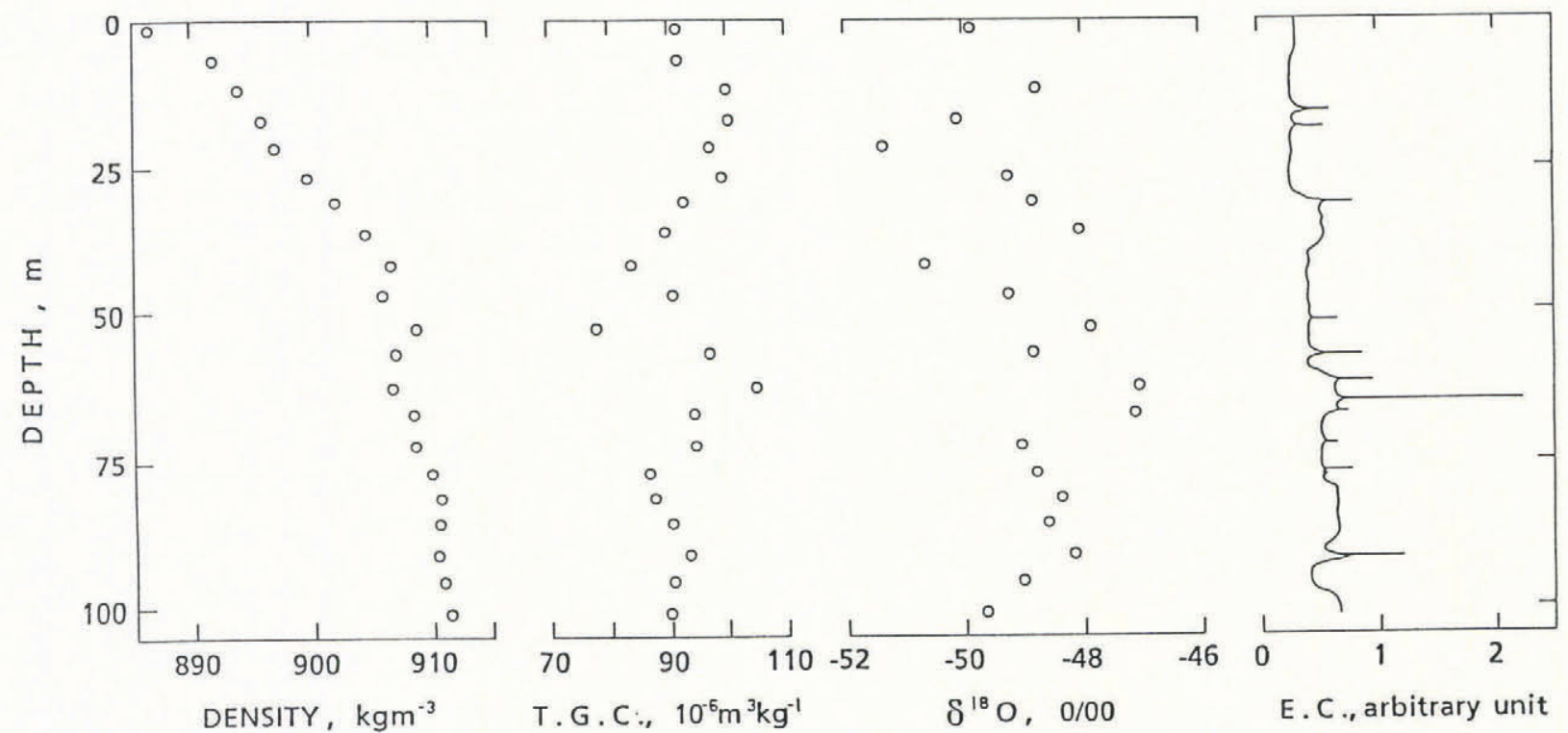

Fig.1. Stratigraphic record of a $100 \mathrm{~m}$ long ice core from the Meteorite Ice Field, Antarctica. T.G.C.: total gas content. 


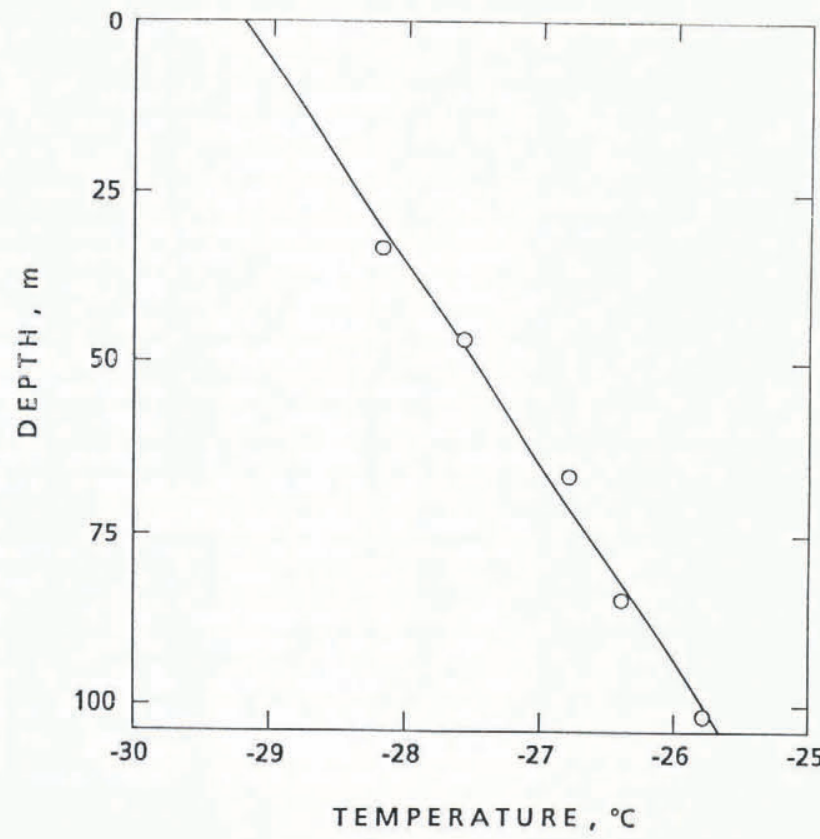

Fig.2. Temperature profile at the drilling site. The solid line shows a linear regression.

Many vertical cracks were found in the shallow part of the core, down to $7 \mathrm{~m}$, whereas there were no cracks at greater depths. The cracks were almost parallel to the flow direction. There were occasional cloudy and clear bands, which were perpendicular to the main axis of the core. No clathrate hydrate inclusions were found after careful observation with a microscope.

For density measurements, specimens of about $0.1 \mathrm{~kg}$ were cut from the core at every $5 \mathrm{~m}$, avoiding the cracks, and the cloudy and clear layers. The measurements were made using the hydrostatic method (Butkovich 1953). Values were corrected for bubbles cut at the sample surfaces, using the procedure of Nakawo and Narita (1985). These density values are shown in Figure 1, after correction for the in-situ temperature (shown in Fig.2), using Bader's (1964) expression for the density - temperature relationship. Density increases gradually with depth, from about $888 \mathrm{~kg} \mathrm{~m}^{-3}$ at $3 \mathrm{~m}$ to about $913 \mathrm{~kg} \mathrm{~m}^{-3}$ at $101 \mathrm{~m}$.

The density samples per se were used for measuring total gas content. Langway's (1958) method was employed for the measurements: the samples were melted in kerosene, and the released air was introduced into a gas burette. Various corrections for the data were made acording to Higashi and others (1983). The results are plotted in Figure 1. The total gas content fluctuates considerably around a value of $90 \times 10^{-6} \mathrm{~m}^{3} \mathrm{~kg}^{-1}$, showing a slight tendency to decrease with depth.

The full length of each $0.5 \mathrm{~m}$ section was used for analyzing $\delta^{18} \mathrm{O}$, so that the seasonal variation in $\delta^{18} \mathrm{O}$ would be averaged and only the long-term trends would be apparent. These data are also shown in Figure 1. The value for $\delta^{18} \mathrm{O}$ varies with depth, in a range between -52 and $-47 \%$.

Electrical conductivity of the ice was measured continuously from the top to the bottom of the core, by the method developed by Hammer (1980). The measurements were made twice, and both sets of results agreed fairly well. The conductivity is shown in Figure 1. Eleven remarkable peaks can be seen in the figure. At three depths (31, 52, and $65 \mathrm{~m}$, the $0.5 \mathrm{~m}$ long core sample was cut into segments of $50 \mathrm{~mm}$. Electrical conductivity of the melt water from each segment was measured. The locations or depths of peaks found in this measurement matched those found for the electrical conductivity of solid ice. The height of the peaks in both measurements also showed a positive correlation, although the agreement was not as good.

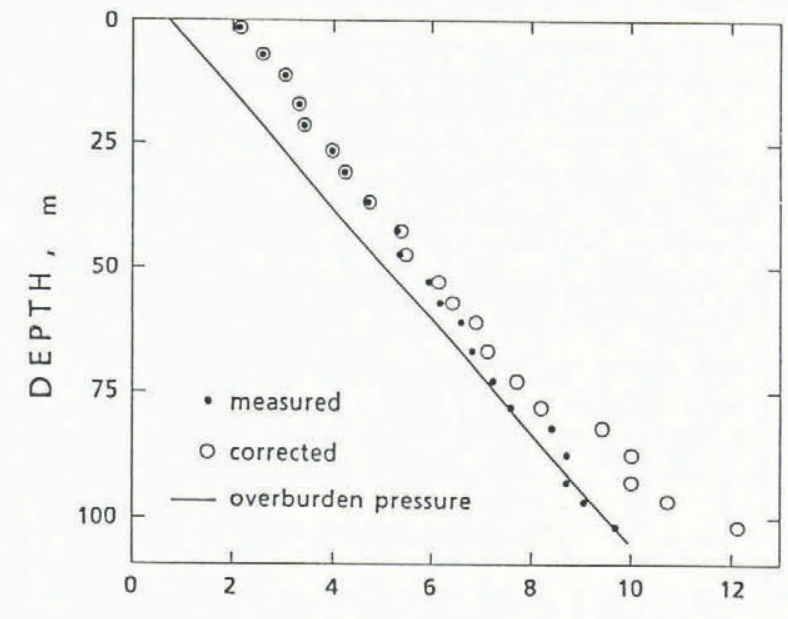

BUBBLE PRESSURE， atm.

Fig.3. Bubble pressure versus depth. Solid circles show the values obtained from the total gas content and densities, which were measured about 16 months after core recovery. The relaxation of the samples during the 16 months was taken into account, and the in-situ pressure was estimated as shown by open circles.

\section{BUBBLE PRESSURE}

Bubble pressure was calculated from the data on density, total gas content (Fig.1), and in-situ temperature distribution (Fig.2). The pressure, about 2 atmospheres near the surface, increases with depth almost linearly, and attains a value of about 10 atmospheres at the bottom of the core (Fig.3). Bubble pressure thus estimated would be different from the in-situ pressure, since the core ice had relaxed (in association with the increase in volume of the bubbles) before the density measurements were carried out, 15-16 months after core recovery.

Jones and Johari (1977) examined the shrinkage of air bubbles in natural and artificial ice under high hydrostatic pressure, and found that the strain-rate of bubbles was in agreement with the uniaxial compressive creep curves of Barnes and others (1971). Shoji and Langway (1983), on the other hand, observed the volume-expansion process of air bubbles in a fresh ice core recovered at Dye 3, Greenland. They analysed the data on the basis of stress/strain-rate relationship, $\dot{\varepsilon}=(\sigma / A)^{\mathrm{n}}$, in which $\dot{\varepsilon}$ refers to the rate of expansion of an air bubble, $\sigma$ is the pressure difference between that of the internal bubbles and the atmosphere, and $\mathrm{A}$ and $\mathrm{n}$ are constants. They found that $\mathrm{n}=2.7$ and $\mathrm{A}$ $=7.8 \times 10^{3} \mathrm{bar} \mathrm{s}^{1 / \mathrm{n}}$ at a temperature of about $-11.5^{\circ} \mathrm{C}$. It was observed, however, that the rate of bubble expansion in polycrystalline ice was not uniform for all bubbles (personal communication from N. Azuma), presumably because it is dependent on the orientation of the host crystal in conjunction with that of the other surrounding crystals. Hence Shoji and Langway's results may not be adequate for estimating the bulk expansion of the core, since they studied a limited number of bubbles. In addition, the volume expansion of an individual bubble is not uniform but anisotropic, e.g. the formation of "crack ring" or subboundary networks as seen in the photographs in Shoji and Langway (1983) and Narita and Nakawo (1985).

Nakawo (1986) examined the volume expansion of core samples by intermittent measurements of their densities. The density-time relation was analysed with an expression which was similar to Shoji and Langway's: $\dot{\varepsilon}=\mathbf{B} \sigma^{\mathrm{n}}$, where $\delta$ is the pressure difference between gases in the internal bubbles and in the atmosphere. It should be noted, however, that in Nakawo's expression $\dot{\varepsilon}$ is not the rate of expansion of a bubble, but that of an ice sample with air inclusions. He obtained the value of $n=3$ and $B=10^{-13} \mathrm{bar}^{-n} \mathrm{~s}^{-1}$ for $-10^{\circ} \mathrm{C}$. These values are still uncertain, because there are many fine cracks in the samples. It is considered, however, that Nakawo's result is the most appropriate one, among stress / strain-rate relationships available at present, for estimating the in-situ bubble pressure from pressure data 
which has been obtained some time after core recovery.

The pressure data thus obtained were corrected for in-situ values, which are shown in Figure 3 . The correction was negligible near the surface, but became significant with increasing depth, as the pressure increased. The bubble pressure was appreciably higher than the overburden pressure (atmospheric pressure plus the cumulative weight of the ice) which had been estimated from the density data.

\section{VERTICAL MOVEMENT OF ICE}

The emergence flow has been observed in the blue-ice areas of Antarctica (Naruse 1978, Nishio and others 1982). When the ice which contains air bubbles at rather high pressure is lifted relative to the surface, the pressure of the bubbles decreases so as to equilibrate with the overburden pressure at the depth of the current location of the bubbles. This is the same process as volume relaxation of core samples which are exposed to relatively low atmospheric pressure after extraction from pressurized depths. The sudden drop in pressure could lead to crack formation, but this is not the case with upward movement where the pressure change is gradual. The deterioration of air hydrate and/or the formation of new bubbles may be another mechanism for volume relaxation. This process, however, can also be excluded in the case of the Yamato core, since no hydrate inclusions were found in it. It is considered, therefore, that the decrease in bubble pressure caused by vertical ice movement is to be attributed solely to expansion of the contained bubbles per se.

If a power law is applied to the volume expansion of the bubbles, the following expression can be given, assuming that the ice field is almost horizontal:

$$
\frac{\partial p_{b}}{\partial t}+v \frac{\partial p_{b}}{\partial y}=-3 K p_{b}\left(p_{b}-p_{0}\right)^{n}
$$

where $\mathrm{p}_{\mathrm{b}}$ and $\mathrm{p}_{0}$ are bubble pressure and overburden pressure respectively, $t$ is time, $y$ is depth, $v$ is vertical velocity, and $\mathrm{n}$ and $\mathrm{K}$ are constants. If the flow is in a steady state, the first term on the left-hand side becomes zero. Hence the vertical velocity $v$ was obtained from the values of $\mathrm{p}_{\mathrm{b}}$ and $\mathrm{p}_{0}$ shown in Figure 3 . In the calculation, the value of $K$ was adjusted to take into account the temperature profile given in Figure 2, which has an activation energy of $0.8 \mathrm{eV}$ (e.g. Hobbs 1974).

Figure 4 shows the estimated velocity $\mathrm{v}$ versus depth. Curve A was obtained on the basis of the flow law for volume expansion given by Nakawo (1986), and curve B was obtained from Shoji and Langway (1983). Both profiles show a similar trend, although the former predicts a velocity five to seven times lower than the latter. The velocity is almost constant (about $3 \mathrm{~mm} / \mathrm{a}$ in $A$ and about $15 \mathrm{~mm} / \mathrm{a}$ in B) at depths above $50 \mathrm{~m}$, but it decreases rapidly with increasing depth.

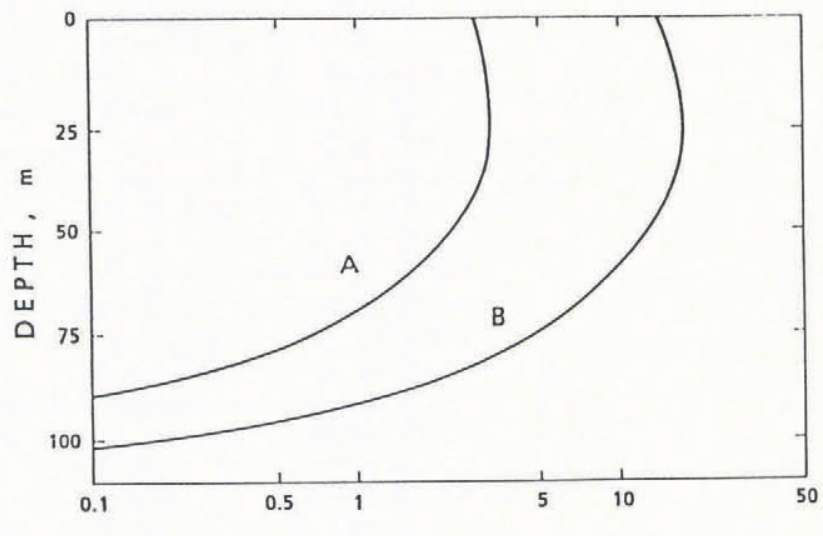

VERTICAL VELOCITY, mm/year

Fig.4. The rate of vertical movement versus depth. A different flow law for the volume expansion of ice gave different profiles (see text).
As can be seen in the differences between the two curves $A$ and $B$, vertical velocity is sensitive to $K$ in the flow law for the bubble expansion. As Nakawo (1986) obtained the value from the time-dependent density data, his value might be more appropriate for estimating mean-pressure decrease than that of Shoji and Langway (1983), which was derived by observing the expansion of a limited number of individual bubbles. Nakawo's sample, however, had a considerable number of cracks, and the correction for the cracks meant there were some uncertainties in $\mathrm{K}$. It would be reasonable, therefore, to conclude that the vertical velocity is of the order of several millimeters per year at depths above, for example, $60 \mathrm{~m}$. For deeper parts of a core, the effect of $\mathrm{K}$ increases both on estimating the in-situ pressure from its measured value and also in deriving the velocity from the pressure.

In the bare ice area, the sublimation rate of surface ice was observed to be $50-70 \mathrm{~mm} / \mathrm{a}$ around the drilling site (Nakawo and others 1984). The ice-ablation rate is much larger than the estimated vertical velocity of the ice's upward movement. This may indicate that the surface of the bare ice field has lowered at a rate of about $50 \mathrm{~mm} / \mathrm{a}$. This lowering could have taken place very recently, since the vertical velocity was the value relative to the surface.

\section{AGE OF ICE}

From the velocity profile it was possible to estimate for every depth, the age of the ice relative to the age of the surface ice, on the assumption of a steady state, which, however, may not be correct (as mentioned above). With the velocities of curve $A$, the difference in age from that of the surface ice became $18 \mathrm{ka}$ at a depth of $50 \mathrm{~m}$ and $40 \mathrm{ka}$ at a depth of $75 \mathrm{~m}$. Curve $\mathrm{B}$, on the other hand, resulted in age differences of 3 and $6 \mathrm{ka}$ at the respective depths.

Because of the uncertainties in $K$, and the flow condition (steady state versus non-steady state), the attempt to determine the age of the core samples was not successful. The stratigraphic record shown in Figure 1, therefore, will not be discussed further. In summary, however, the rather short core may have preserved the information on past climate and/or the ice sheet over as long as $10^{4}-10^{5} \mathrm{a}$. The ice may have been deposited during the last glacial period, since the terrestrial age of meteorites found in the Yamato meteorite ice field was estimated to be less than $40-70 \mathrm{ka}$ (e.g. Schultz 1986).

\section{ACKNOWLEDGEMENTS}

The authors are grateful to Dr Y Ageta of the Water Research Institute, Nagoya University, for analyzing $\delta^{18} \mathrm{O}$. This study was partly supported by a Grant-in-Aid for Scientific Research from the Japanese Ministry of

Education, Science and Culture.

\section{REFERENCES}

Azuma N, Nakawo M, Higashi A, Nishio F 1985 Flow pattern near Massif $A$ in the Yamato bare ice field estimated from the structures and the mechanical properties of a shallow ice core. Memoirs of National Institute of Polar Research. Special Issue 39: 173-183

Bader H 1964 Density of ice as a function of temperature and stress. CRREL Special Report 64

Barnes P, Tabor D, Walker J C F 1971 The friction and creep of polycrystalline ice. Proceedings of the Royal Society of London Ser A 324(1557): 127-155

Butkovich T R 1953 Density of single crystals of ice from a temperate glacier. Snow, Ice and Permafrost Research Establishment. Research Paper 7

Cassidy W A, Olsen E, Yanai K 1977 Antarctica: a deep-freeze storehouse for meteorites. Science 198(4318): 727-731

Hammer C U 1980 Acidity of polar ice cores in relation to absolute dating, past volcanism, and radio-echoes. Journal of Glaciology 25(93): 359-372

Higashi A, Nakawo E, Enomoto H 1983 The bubble close-off density of ice in Antarctic ice sheets. Memoirs of National Institute of Polar Research. Special Issue 29: $135-148$

Hobbs P V 1974 Ice physics. Oxford, Clarendon Press 
Jones S J, Johari G P 1977 Effect of hydrostatic pressure on air bubbles in ice. International Association of Hydrological Sciences Publication 118 (General Assembly of Grenoble 1975-Isotopes and Impurities in Snow and Ice): $23-28$

Langway C C Jr 1958 Bubble pressures in Greenland glacier ice. International Association of Scientific Hydrology Publication 47 (Symposium Chamonix - Physics of the Motion of Ice): 336-349

Nagata T 1978 A possible mechanism of concentration of meteorites within the meteorite ice field in Antarctica. Memoirs of National Institute of Polar Research. Special Issue 8: 70-92

Nakawo M 1986 Volume expansion of a 413.5-m Mizuho core after its recovery. Memoirs of National Institute of Polar Research. Special Issue 45: 78-85

Nakawo M, Narita H 1985 Density profile of a $413.5 \mathrm{~m}$ deep fresh core recovered at Mizuho Station, East Antarctica. Memoirs of National Institute of Polar Research. Special Issue 39: 141-156

Nakawo M, Narita H, Isobe T 1984 Glaciological research program in east Queen Maud Land, East Antarctica. Part 2. 1983 JARE Data Reports 96

Narita H, Nakawo M 1985 Structure of 413.5-m deep ice core obtained at Mizuho Station, Antarctica. Memoirs of National Institute of Polar Research. Special Issue 39: 157-164

Naruse R 1978 Surface flow and strain of the ice sheet measured by a triangulation chain in Mizuho Plateau. Memoirs of National Institute of Polar Research. Special Issue 7: 198-226

Nishio F, Azuma N, Higashi A, Annexstad J O 1982 Structural studies of bare ice near the Allan Hills, Victoria Land, Antarctica: a mechanism of meteorite concentration. Annals of Glaciology 3: 222-226

Schultz L 1986 Terrestrial ${ }^{81} \mathrm{Kr}$-ages of four Yamato meteorites. Memoirs of National Institute of Polar Research. Special Issue 41: 319-327

Shoji H, Langway C C Jr 1983 Volume relaxation of air inclusions in a fresh ice core. Journal of Physical Chemistry 87(21): 4111-4114

Whillans I M, Cassidy W A 1983 Catch a falling star: meteorites and old ice. Science 222(4619): 55-57

Yanai K 1979 Catalog of Yamato meteorites in the collection of National Institute of Polar Research. Tokyo, National Institute of Polar Research. 